\title{
Triptolide, a HSP90 middle domain inhibitor, induces apoptosis in triple manner
}

\author{
Frederick Zhehao Zhang ${ }^{1,2, *}$, Derek Hoi-Hang Ho ${ }^{1, *}$ and Roger Hoi-Fung Wong ${ }^{1}$ \\ ${ }^{1}$ Department of Biology, Hong Kong Baptist University, Hong Kong SAR, Hong Kong \\ ${ }^{2}$ Department of Chemistry, University of Hong Kong, Hong Kong SAR, Hong Kong \\ *These authors contributed equally to this work \\ Correspondence to: Roger Hoi-Fung Wong, email: rogerwong@hkbu.edu.hk \\ Keywords: triptolide; HSP90; CDC37; apoptosis; cancer
}

Received: October 13,2017 Accepted: February 24, $2018 \quad$ Published: April 27, 2018

Copyright: Zhang et al. This is an open-access article distributed under the terms of the Creative Commons Attribution License 3.0 (CC BY 3.0), which permits unrestricted use, distribution, and reproduction in any medium, provided the original author and source are credited.

\section{ABSTRACT}

Triptolide (TL) is a potent anti-tumor, anti-inflammatory and immunosuppressive natural compound. Mechanistic studies revealed that TL inhibits tumor growth and triggers programmed cell death. Studies further suggested that TL inhibits heat shock response in cancer cells to induce apoptosis. HSP90 $\beta$ is the major component of heat shock response and is overexpressed in different types of cancers. Given almost all identified HSP9OB inhibitors are either $\mathbf{N}$ or C-terminal inhibitors, small molecules attacking cysteine(s) in the middle domain might represent a new class of inhibitors. In the current study, we showed that TL inhibits HSP90 $\beta$ in triple manner. Characterization suggests that TL inhibits ATPase activity by preventing ATP binding thus blunts the chaperone activity. TL disrupts HSP9OB-CDC37 (co-chaperone) complex through middle domain Cys366 of HSP90 $\beta$ and causes kinase client protein degradation. At the cellular level, the TL-mediated decrease in CDK4 protein levels in HeLa cells causes reduced phosphorylation of $\mathbf{R b}$ resulting in cell cycle arrest at the G1 phase. Furthermore, our results demonstrated that TL triggers programmed cell death in an HSP9Oß-dependent manner as knockdown of HSP9Oß further sensitized TL-mediated cell cycle arrest and apoptotic effect. Surprisingly, our data showed that TL is the first drug to be reported to induce site-specific phosphorylation of HSP9O $\beta$ to drive apoptosome formation in the early phase of the treatment.

In summary, our study established that TL is a novel middle domain HSP90 $\beta$ inhibitor with bi-phasic multi-mechanistic inhibition. The unique regulatory mechanism of TL on HSP90 $\beta$ makes it an effective inhibitor.

\section{INTRODUCTION}

Molecular chaperones facilitate proper protein folding and allow protein complex to assemble effectively [1]. The function of molecular chaperones is critical to cellular survivals. However, molecular chaperones are double-edge swords as they prevent oncoproteins from misfolding and degradation in cancer cells [2]. Chaperones are highly expressed and heat shock responses are constitutively activated in cancer cells. Different chaperones, such as HSP90 $\beta$, HSP70 and HSP27, were reported to have oncogenic functions [3]. HSP90 $\beta$ is the major component of heat shock response and is overexpressed in different types of cancers. HSP90 $\beta$ is a critical factor for cancer cell survival and oncogene addiction. Homodimeric HSP90 $\beta$ has 3 distinct domains: $\mathrm{C}$-terminal, middle and $\mathrm{N}$-terminal domains. C-terminal domain of HSP90 $\beta$ is responsible for dimerization and tetratricopeptide repeats (TPR) co-chaperone recognition. The middle domain interacts with most of the non-TPR co-chaperones and client proteins. And ATP-binding pocket is located in the N-terminal domain [4-6]. The conformation and chaperone activity of HSP90 $\beta$ is regulated by ATP and co-chaperones including HOP, CDC37, p23 and Aha1. HSP90 $\beta$ and its co-chaperones work in concert to regulate the conformation and activity 
of a large variety of signalling molecules, transcription factors and cytoskeletons in response to different cellular stresses [7].

A number of oncogenic client proteins are chaperoned by HSP90 $\beta$, such as Raf-1, IKK-1/2 and AKT-1, which are involved in different signal transduction pathways during cancer development [8]. Dysfunction of HSP90 $\beta$ by HSP90 $\beta$ inhibitors leads to degradation of its client proteins and triggers programmed cell death $[9,10]$. Several studies demonstrated that HSP90 $\beta$ complexes in tumor cells have much higher affinity for ATP and HSP90 $\beta$ inhibitors when compared to those in normal cells, therefore suggesting the therapeutic potential of HSP90 $\beta$ inhibitors for killing cancer cells due to their high selectivity [11-13]. The chaperone activity of HSP90 $\beta$ is required for associating with client proteins and co-chaperones. CDC37 is a non-TPR co-chaperone of HSP90 $\beta$ which was first identified as a cell cycle regulator in budding yeast. Study showed that CDC37 is responsible for recruitment of premature kinase client proteins to HSP90 $\beta[14,15]$. CDC37 deficiency reduces HSP90 $\beta$-CDC37 dependent kinases and increases drug sensitivity of HSP90 $\beta$ inhibitors [16]. On the other hand, recent study showed that $\mathrm{CDC} 37$ slows down HSP90 $\beta$ dimer twisting rate without affecting nucleotide accessibility to its binding site(s) [17]. Further evidences suggest CDC37 binds to both N-terminus and middledomain of HSP90 $\beta$ and restricts its mobility [18]. Most of the HSP90 $\beta$ inhibitors have no effect on the interaction of HSP90 $\beta$-CDC37 complexes. Natural products Celastrol (CEL) and withaferin A (WA) are the only two identified HSP90 $\beta$ inhibitors that destabilize HSP90 $\beta$-CDC37 complexes through unknown mechanism $[19,20]$. Given almost all identified inhibitors such as ganetespib are either $\mathrm{N}$ or C-terminal inhibitors [21], small molecules attacking cysteine(s) in the middle domain may represent a new class of inhibitors that is distinct from those targeting either the N-terminal ATP-binding pocket or the C-terminal dimerization domain of HSP90 $\beta$ [22].

Triptolide (TL), isolated from Tripeterygium wilfordii Hook f. (TwHf), exhibits diversified biological activities including anti-proliferation, cytotoxicity, immune modulation and anti-inflammation [23]. Mechanistic studies revealed that TL inhibits tumor growth and triggers programmed cell death through both p53 dependent and independent death-receptor signaling pathway and mitochondria-mediated apoptotic pathway [24-26]. Studies suggested that TL inhibits HSP70 activity in pancreatic cancer cells to induce apoptosis by suppression of HSF-1 [27]. In the present study, we have shown that TL inhibits HSP90 $\beta$ ATPase activity and attacks middle domain cysteine to block the interaction between HSP90 $\beta$ and CDC37. Our further characterization has revealed that TL as a novel inhibitor of HSP90 $\beta$ induces apoptosis in triple manner. We demonstrated that TL has a unique biphasic inactivation of HSP90 $\beta$ through cysteine modification and post-transitional modification of HSP90 $\beta$ in a time dependent manner. To date, TL is the first drug reported to have an effect on the site-specific phosphorylation of HSP90 $\beta$ that is critical for apoptosome formation. TL, a novel middle domain inhibitor, inhibits the ATPase and chaperone activity of HSP90 $\beta$ to induce apoptosis.

\section{RESULTS}

\section{Triptolide inhibits ATPase activity of HSP90及 and disrupts its chaperone activity}

Since TL was reported to trigger cellular apoptosis through HSP70 inhibition, we would like to investigate if the apoptotic effect of TL was mediated by HSP90 $\beta$, the critical molecular chaperone with anti-apoptotic activities. ATPase activity is crucial to the function of HSP90 $\beta$ chaperone activity as HSP90 $\beta$ dimerization and co-chaperone recruitment are facilitated by its activity. We first measured the ATPase activity of HSP90 $\beta$ in the presence of TL at various concentrations. A dosedependent inhibition of HSP90 $\beta$ ATPase by TL was observed by incubating $1 \mu \mathrm{M}$ of HSP90 $\beta$ with increasing concentrations of TL for three hours, of which $\mathrm{IC}_{50}$ of TL on HSP90 $\beta$ ATPase activity is $29.9 \mu \mathrm{M}$ (Figure 1A). Studies have shown that the epoxide group of triptolide, which is the reactive electrophile for thiols, is involved in the covalent modification of cysteines [28]. Out of the 6 cysteines in HSP90 $\beta$ 's middle domain and C-terminal, 2 of those at 366 and 590 are exposed and are critical for its ATPase activity and dimerization respectively [29]. We next asked whether these cysteines are required for TL to mediate the inhibition on the ATPase activity by examining the effect of TL on ATPase activity of different HSP90 $\beta$ mutants. In Figure 1B, HSP90 $\beta^{\mathrm{C} 366 \mathrm{~S}}$ showed similar ATPase activity when compared to HSP90 $\beta^{\mathrm{WT}}$ indicating cys366 is not a crucial site to modulate its ATPase activity. Furthermore, TL exhibited a similar inhibitory effect on both HSP90 $\beta^{\mathrm{WT}}$ and HSP90 $\beta^{\mathrm{C} 366 \mathrm{~S}}$ suggesting that TL suppresses the ATPase activity of HSP90 $\beta$ independent of Cys366. Unlike HSP90 $\beta^{\mathrm{C} 366 \mathrm{~S}}$, in the absence of TL, both HSP90 $\beta^{\mathrm{C} 590 \mathrm{~S}}$ and double mutant HSP90 $\beta^{\mathrm{C} 366 / 590 \mathrm{~S}}$ only showed marginal ATPase activity as Ruiz et al [30] reported that cysteine 590 is a regulatory site for its ATPase activity. Incubation with or without TL with either HSP90 $\beta^{\mathrm{C} 590 \mathrm{~S}}$ or HSP90 $\beta^{\mathrm{C} 366 / 590 \mathrm{~S}}$ did not have any further effect on the ATPase activity suggesting that TL-mediated suppression of the activity could be further blunted by modifying Cys590.

Further validating our hypothesis, MANT-ADP releasing assay was employed to investigate the effect of TL on the nucleotide-HSP90 $\beta$ interaction. Similar to ATPase activity, Figure $1 \mathrm{C}$ showed that mutation of cysteine 366 had no effect on TL's inhibition of MANTADP interacting with ATP binding pocket. However, the 
A

TL's inhibitory effect on HSP90 ATPase activity
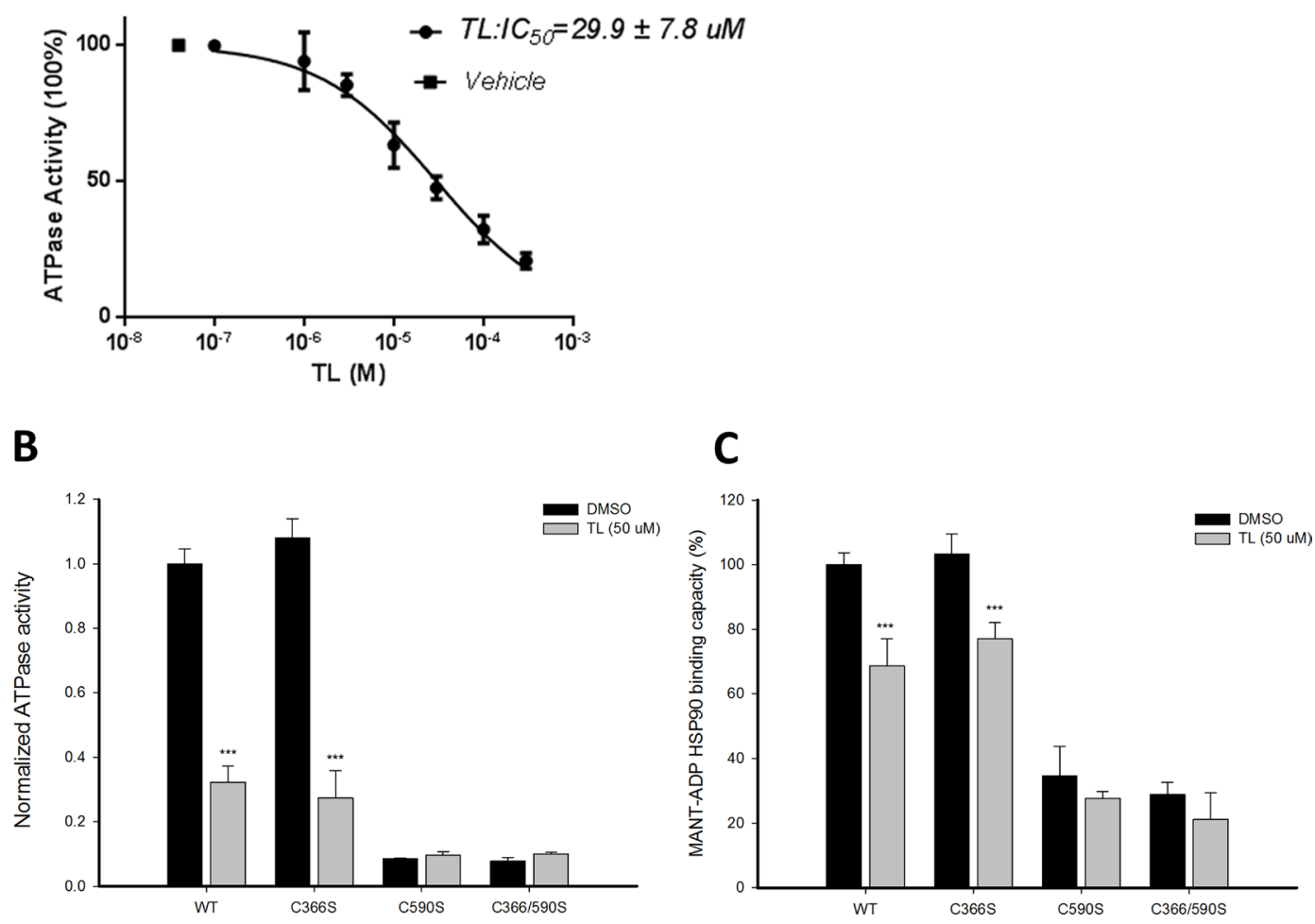

D
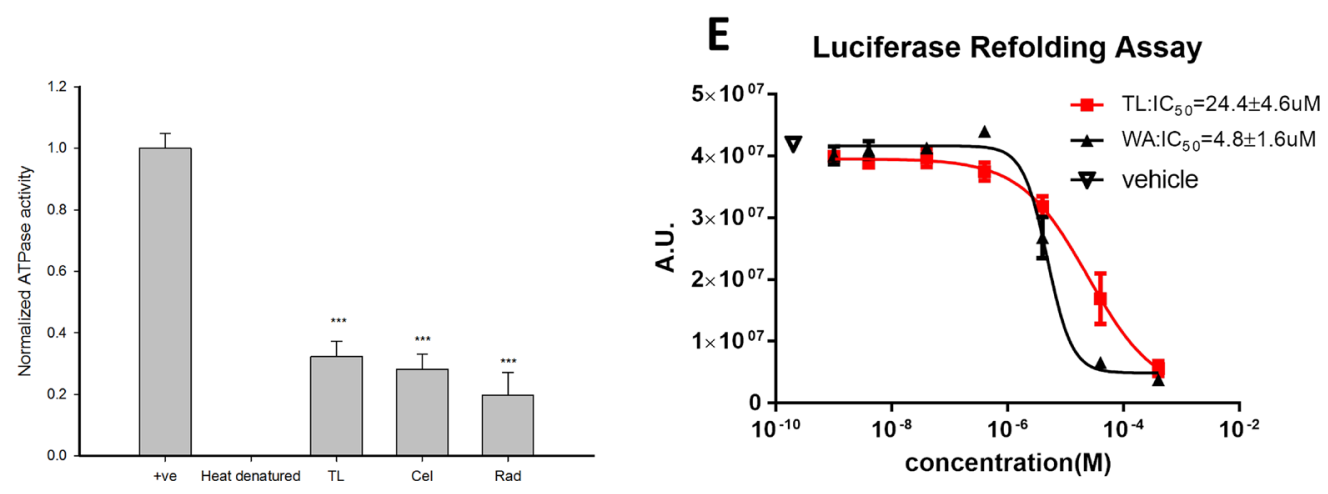

Figure 1: Triptolide inhibits ATPase activity of HSP90 $\beta$ and disrupts its chaperone activity. (A) TL inhibits ATPase activity of HSP90 $\beta$ in a dosage-dependent manner. Colorimetric ATPase activity assay was performed with different concentrations of TL and DMSO as vehicle control. TL's $\mathrm{IC}_{50}$ on the ATPase activity of $\mathrm{HSP} 90 \beta$ was determined from three independent experiments. Data are represented as mean $\pm \mathrm{SD}(n=3)$. (B) Colorimetric ATPase activity assay was performed with different HSP90 $\beta$ mutants. Recombinant HSP90 $\beta$ (WT and different mutants) was incubated with $50 \mu \mathrm{M} \mathrm{TL}$ at $4^{\circ} \mathrm{C}$ for $3 \mathrm{hrs}$, and reaction mixture from assay kit was added and incubated at $37^{\circ} \mathrm{C}$ for another $1 \mathrm{hr}$. Absorbance at $650 \mathrm{nM}$ was measured and result from vehicle (DMSO)-treated wild-type HSP90 $\beta$ group was normalized as 1. ${ }^{* * *} P<0.001$ DMSO versus TL. Data are represented as mean $\pm \mathrm{SD}(n=3)$. (C) MANT-ADP binding assay with different HSP90 $\beta$ mutants in the presence of TL. Recombinant HSP90 $\beta$ (WT and different mutants) was incubated with $50 \mu \mathrm{M} \mathrm{TL}$ at $4^{\circ} \mathrm{C}$ for $3 \mathrm{hrs}$. MANT-ADP was then added to the reaction mixture. The reaction mixture was incubated for additional 1 hour at $37^{\circ} \mathrm{C}$ and analyzed with excitation at 370 $\mathrm{nM}$ and emission at $465 \mathrm{nM}$. Result from vehicle (DMSO)-treated wild-type HSP90 $\beta$ group was set as $100 \%$ binding capacity. ${ }^{* * *} P<0.001$ DMSO versus TL. Data are represented as mean $\pm \mathrm{SD}(n=3)$. (D) ATPase activity of HSP90 $\beta$ upon treatment of TL and different inhibitors. Recombinant HSP90 $\beta$ was incubated with $50 \mu \mathrm{M}$ TL, CEL and RAD. Heat-denatured recombinant HSP90 $\beta$ was served as positive control. Colorimetric ATPase activity assay was performed as described above. ${ }^{* * * *} P<0.001$ different inhibitors versus heat denatured group. Data are represented as mean $\pm \mathrm{SD}(n=3)$. (E) TL inhibits chaperone activity of HSP90 $\beta$. HSP90 $\beta$ chaperone activity in the presence of TL and WA at different concentrations. $\mathrm{IC}_{50}$ was determined from three independent experiments by measuring the amount of refold heat-denatured luciferase in rabbit reticulocyte lysate. To perform heat denaturing, luciferase was heated at $41^{\circ} \mathrm{C}$ for $10 \mathrm{~min}$. Rabbit reticulocyte lysate was added to heat-denatured luciferase in the presence of TL and WA in different concentrations, and incubated at $4^{\circ} \mathrm{C}$ for $3 \mathrm{hrs}$. Luciferase assay buffer were then added and incubated at room temperature for 5 mins. Luminescence signal was measured with integration time of $400 \mathrm{~ms}$. $\mathrm{IC}_{50}$ was determined from three independent experiments. Data are represented as mean $\pm \mathrm{SD}(n=3)$. 
interaction between either HSP90 $\beta^{\mathrm{C} 590 \mathrm{~S}}$ or HSP90 $\beta^{\mathrm{C} 366 / 590 \mathrm{~S}}$ and MANT-ADP was significantly blocked regardless of treatment of TL. Consistent with TL's effect on ATPase activity of HSP90 $\beta$, TL weakened the interaction between nucleotides and HSP90 $\beta^{\mathrm{WT}}$ or HSP90 $\beta^{\mathrm{C} 366 \mathrm{~S}}$ while it had no effect on neither HSP90 $\beta^{\mathrm{C} 590 \mathrm{~S}}$ nor HSP90 $\beta^{\mathrm{C366/590S}}$. Given cys590 is the regulatory site for ATPase activity, the likelihood of TL inhibiting ATPase activity of HSP90 $\beta$ through modification of cys590 could not be ruled out. We next compared the inhibitory effect of TL alongside with other well characterized HSP90 $\beta$ inhibitors. Figure 1D showed similar inhibitory effect on ATPase activity of HSP90 $\beta$ among $50 \mu \mathrm{M}$ of TL, CEL and RAD treatment.

We then sought the functional consequence of TLmediated inhibition of ATPase activity of HSP90 $\beta$ on its chaperone activity. Luciferase refolding assay was conducted in HSP90 $\beta$-rich rabbit reticulocyte lysate [31]. Incubation of TL in rabbit reticulocyte lysate prohibited HSP90 $\beta$ from restoring heat-denatured luciferase activity in a dose dependent manner with an apparent $\mathrm{IC}_{50}$ of 24.4 $\mu \mathrm{M}$ (Figure 1E). WA served as a positive control and its apparent $\mathrm{IC}_{50}$ of $4.8 \mu \mathrm{M}$ which matched the reported value. Notably, $\mathrm{IC}_{50}$ of $\mathrm{TL}$ in both luciferase refolding assay and ATPase assay are in the similar range suggesting the shutdown of HSP90 $\beta$ chaperone machinery is dependent on its ATPase activity.

\section{Triptolide attacks the middle domain to detablize the HSP90ק-CDC37 interaction}

Given that TL inhibits intrinsic ATPase activity and chaperone activity of HSP90 $\beta$ in vitro, we next examined whether TL could inhibit the chaperone activity in cultured cells. TL has been reported to inhibit the proliferation of all 60-NCI cancer cell lines including HeLa with an IC50 in the nanomolar range $[32,33]$, and HeLa cells have been adopted to study the anti-proliferative effect of TL $[28,34]$. Treating HeLa cells with TL at $30 \mathrm{nM}$ or higher concentrations drastically reduced protein levels of Raf-1, a client protein of HSP90 $\beta$ (Figure 2A). We also detected that Raf-1 was highly ubiquinated in the presence of TL (Supplementary Figure 1). In contrast, no significant change was observed in protein levels of other HSP90 $\beta$ client proteins such as AKT-1 in response to TL treatment. Abundance of HSP90 $\beta$ and co-chaperone CDC37, however, was unchanged in the presence of TL. These results suggest that TL impairs HSP90 $\beta$ machinery without affecting protein levels of the chaperone complex (Figure 2A). It has been reported that TL interacts with XPB to inhibit universal transcription, thus we tested whether TL could specifically down-regulate mRNA levels of HSP90 $\beta$ client proteins and co-chaperones. Surprisingly, TL treatment at $100 \mathrm{nM}$ for 24 hours did not change the mRNA levels of HSP90 $\beta$, its client proteins, co-chaperone and cofactors (Figure 2B). These results indicate that impairment of HSP90 $\beta$ chaperone machinery by TL is independent of transcriptional and post-translational regulation in HeLa cells.

Intrigued by study demonstrated that function of Raf- 1 requires both active HSP90 $\beta$ and its co-chaperone CDC37 [35] and our observed reduction of Raf-1, we next investigated whether TL could have any direct effect on the HSP90 $\beta-C D C 37$ complex as TL does not affect either protein or gene expression of CDC37 as shown previously. His-tagged CDC37 was incubated with HSP90 $\beta$ prior to in-vitro His pull-down assay in the presence of different known HSP90 $\beta$ inhibitors including novobiocin (NOV), radicicol (RAD) and celastrol (CEL). While a strong interaction was detected between HSP90 $\beta$ and CDC37 in the absence of inhibitors, TL and CEL treatment disrupted the HSP90 $\beta$-CDC37 complex (Figure 2C, left panel), and HSP90 $\beta$ inhibitors NOV and RAD did not have obvious effect on the HSP90 $\beta-C D C 37$ interaction. Consistent with published studies, a significantly reduced amount of wild type HSP90 $\beta$ was co-pulled down by CDC37 when pretreated with CEL compared to control group. To dissect the exact mechanism employed by TL to disrupt the HSP90 $\beta$-CDC37 complex, different HSP90 $\beta$ mutants carrying the exposed cysteines were incubated with CDC37 in the presence or absence of TL (Figure 2C, right panel). In the absence of TL, comparable amount of wildtype HSP90 $\beta$ and HSP90 $\beta$ mutants (C366S and C590S) could be co-pulled down by $\mathrm{CDC} 37$ indicating that mutation of either cysteine 366 or 590 has no direct effect on the interaction between HSP90 $\beta$ and CDC37. However, for the mutant HSP90 $\beta^{\mathrm{C} 366 \mathrm{~S}}$, CDC37 was able to capture similar amounts of HSP90 $\beta$ even in the presence of TL indicating that TL disrupts HSP90 $3-C D C 37$ complexes through Cys366. Taken together, TL disrupts the interaction between CDC37 and HSP90 $\beta$ mainly through modification of middle domain cysteine of HSP90 $\beta$ despite that the site has no effect on the interaction itself.

In order to test whether TL could have any effect on CDC37 to disrupt the interaction, we next investigated the interaction between drug pretreated CDC37 and HSP90 $\beta$. Results showed that HSP90 $\beta$ alone could pull down CDC37 regardless pretreatment of TL or CEL with CDC37. However, only TL treated HSP90 $\beta$ destabilized the HSP90 $\beta$-CDC37 complexes among all experimental groups (CDC37 upon control, TL and CEL pretreatment) (Figure 2D). Non-reducing gel WB also revealed that TL, CEL and WA caused no significant change in oligomeric status of CDC37 (Supplementary Figure 2A). Given TL has no effect on CDC37, TL effects on HSP90 $\beta$ to disrupt its interaction with CDC37.

We further examined the effect of TL on the disruption of the HSP90 $\beta$-CDC37 interaction in cultured cells. In the presence of TL or CEL, HSP90 $\beta$ could not be co-purified with FLAG-tagged CDC37 in HEK-293T cells. In contrast, ATP, NOV and RAD treatments had no effect on the interaction between the two as indicated by the positive outcome of the co-purification of HSP90 $\beta$ 
with CDC37 (Figure 2E). Time course study and dosedependent experiment of TL in HEK-293T cells also revealed that TL disrupted HSP90 $\beta$-CDC37 complex in both time dependent and dosage dependent manners (Supplementary Figure 2B). Overall, these data showed that TL disrupts the interaction between HSP90 $\beta$ and CDC37 in cultured cells.

\section{Triptolide inhibits HSP90 $\beta$ to arrest cell cycle and triggers programmed cell death}

Since CDC37 controls cell cycle division, we next explored TL's effect on cell cycle profiling in cultured cells. Flow cytometry analysis revealed that TL could result in significant cell cycle arrest of HeLa cells at G1
A

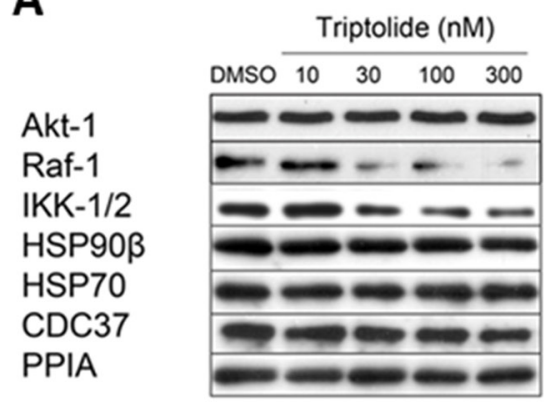

C

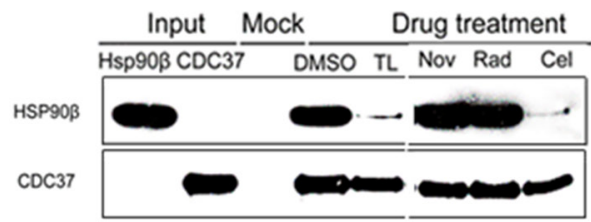

B

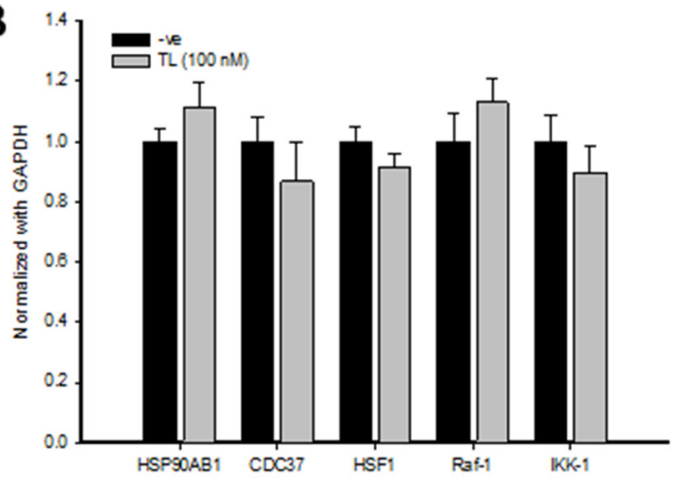

D

\begin{tabular}{|c|c|c|}
\hline \multirow[b]{2}{*}{ CDC37 treatment: } & HSP90 $\beta$ alone & HSP90ß-TL Complex \\
\hline & DMSO TL Cel & DMSO TL Cel \\
\hline HSP90 & 0 & \\
\hline $\operatorname{CDC} 37$ & & \\
\hline
\end{tabular}

$\mathbf{E}$

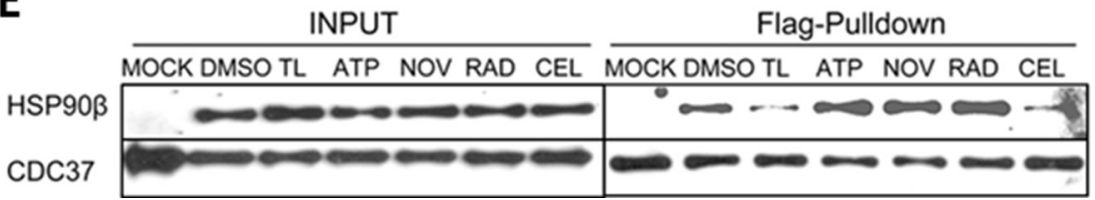

Figure 2: Triptolide destablizes HSP90ß-CDC37 complexes and causes selective client protein degradation. (A) TL selectively decreases levels of HSP90 $\beta$ client proteins in HeLa cells in a dosage-dependent manner. Western blotting of HSP90 $\beta$ client proteins and co-chaperones 24 hours after TL treatment (10, 30, 100 and $300 \mathrm{nM}$ ) in HeLa cells. (B) TL does not regulate transcription levels of HSP90 $\beta$ 's client proteins and co-chaperones. RT-PCR analysis of HSP90 $\beta$ client proteins and co-chaperones 24 hours after TL treatment in HeLa cells. Expression level of client proteins and co-chaperones was normalized with GAPDH. (C) TL and CEL disrupts the interaction between HSP90 $\beta$ and CDC37 in vitro. Recombinant HSP90 $\beta$ were incubated with His-tagged CDC37 in the presence of TL and different inhibitors (NOV, RAD and CEL) in vitro prior to Ni-NTA pulldown. Western blotting analysis of eluates using anti-HSP90 $\beta$ and anti-CDC37. Results represented from three independent studies were shown (left). Different HSP90 $\beta$ mutants were incubated with Histagged CDC37 in the presence of TL in vitro prior to CDC37 immunoprecipitation. Western blotting analysis of in vitro immunoprecipitated and representative image from three independent experiment was shown (right). (D) TL dissociates HSP90 3 -CDC37 complex by binding to HSP90 $\beta$ alone. CDC37 was pretreated with various drugs and unbound drugs were washed out, followed by incubation with HSP90 $\beta$ and HSP90 $\beta$ /TL complex (HSP90 $\beta$ pre-treated with TL) respectively. CDC37 immunoprecipitation was performed and western blotting analysis of in vitro immunoprecipitated mixture was shown and image was represented from three independent experiment. (E) TL and CEL disrupts the interaction between HSP90 $\beta$ and CDC37 in cultured cells. Co-immunoprecipitation of flag-tagged CDC37 and streptagged HSP90 $\beta$ by anti-FLAG antibodies upon 6 hrs' pre-treatment of TL and different inhibitors in HEK-293T cells and immunoblotted with streptavidin-HRP (HSP90 $\beta$ ) and anti-flag antibody (CDC37). Image was represented from three independent experiment. 
phase in a dosage dependent manner which was indicated by a significant accumulation of cells at G0/G1 phase and an obvious reduction of cells at $\mathrm{S}$ phase (Figure 3A, left panel). CDK4, a client protein of HSP90 $\beta-C D C 37$ complexes, is responsible for cell cycle progression from $\mathrm{G} 1$ to $\mathrm{S}$ phase. We then asked whether TL-mediated disruption of HSP90 $\beta$-CDC37 complexes could induce cell cycle arrest through decreasing CDK4 protein levels. Western blotting showed that treatment of TL at $30 \mathrm{nM}$ and $100 \mathrm{nM}$ in HeLa cells substantially reduced CDK4 protein levels. Phosphorylation of $\mathrm{Rb}$, the immediate downstream target of CDK4 to regulate cell cycle check- point at late G1 phase, was also reduced by TL in a dosage dependent manner (Figure 3A, right panel).

In order to examine the requisite role of HSP90 $\beta$ in TL-mediated cell cycle arrest, we tested the biological consequences of TL's effect on HSP90 $\beta$-deficient HeLa cells. Knockdown of HSP90 $\beta$ using corresponding siRNA was efficiently conducted and expression at both transcriptional level (70\% reduction) and translational level (90\% reduction) was reduced (Figure 3B). Similar to our previous results, flow cytometry analysis revealed that knockdown of HSP90 $\beta$ marginally accumulated HeLa cells in G1/G0 phase when compared with control

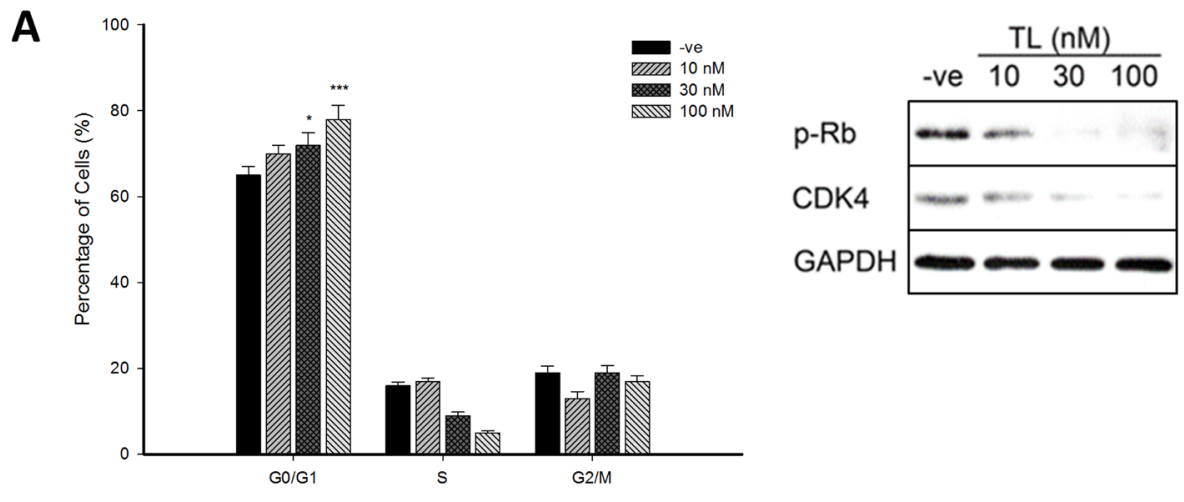

B
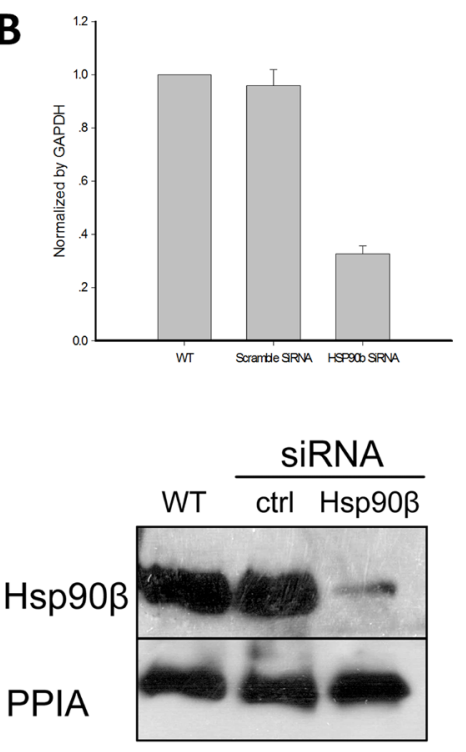

C
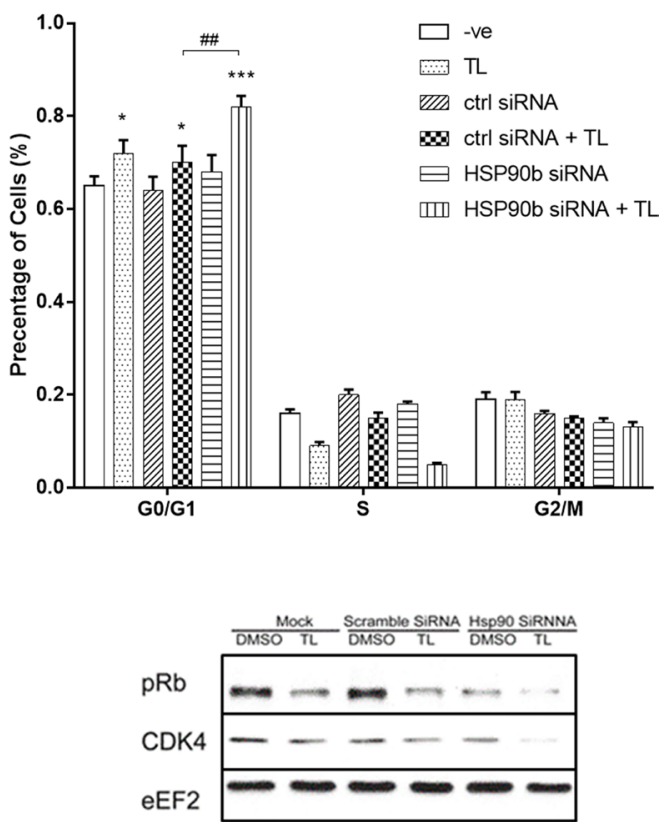

Figure 3: Triptolide arrests HeLa cell cycle through HSP90 $\beta$. (A) TL induces cell cycle arrest of HeLa at G1/G0 phase in a dosage dependent manner. Flow cytometry analysis (left) of cell cycle profiles of HeLa cells upon 24 hrs' TL treatment (10, 30 and 100 $\mathrm{nM}) .{ }^{*} P<0.05 ;{ }^{* * *} P<0.001$ compared with vehicle control. Data are represented as mean $\pm \mathrm{SD}(n=3)$. Western blot analysis (right) of cell cycle related proteins in HeLa cells at various TL concentrations for 24 hrs. Representative image from three independent experiment was shown. (B) Knockdown efficiency of HSP90 $\beta$ by siRNA. mRNA (upper) and protein (lower) level of HSP90 $\beta$ in HeLa cells upon transfection either with control siRNA or HSP90 $\beta$ siRNA was measured. Data are represented as mean \pm SD $(n=3)$. $(\mathbf{C})$ Knockdown of HSP90 $\beta$ sensitizes TL's cell cycle arrest effect on HeLa cells. Flow cytometry analysis (upper) of cell cycle profiles of HeLa cells transfected either with control siRNA or HSP90 $\beta$ siRNA in the presence and absence of TL for 24 hrs. ${ }^{*} P<0.05$; ${ }^{* * *} P<0.001$ vehicle versus TL. ${ }^{\#} P<0.01$ ctrl siRNA+TL versus HSP90 $\beta$ siRNA+TL. Data are presented as mean \pm SD $(n=3)$. Western blot analysis (lower) of cell cycle-related proteins in HeLa cells transfected either with control siRNA or HSP90 $\beta$ siRNA in the presence and absence of TL for $24 \mathrm{hrs}$. Representative image from three independent experiment was shown. 
siRNA transfected cells. TL treatment significantly further increased HeLa cell arrested in G1/G0 phase in HSP90 $\beta$ deficient cells. In contrast, there was no difference between percentages of cells being arrested in G1/G0 phase in TL-treated control siRNA transfected cells and in TL-treated non-transected cells. Importantly, TLtreated HSP90 $\beta$-knockdown cells showed significant and substantial accumulation in G1/G0 phase when compared with TL-treated control siRNA transfected cells $(p<0.01)$ indicating the importance of HSP90 $\beta$ on the cytotoxic effect of TL (Figure 3C, upper panel). In line with the flow cytometry data, knockdown of HSP90 $\beta$ alone decreased CDK4 protein expression and phosphorylation levels of $\mathrm{Rb}$ while $\mathrm{TL}$ treatment potentiated the reduction (Figure
$3 \mathrm{C}$, lower panel). Taken together, knockdown of HSP90 $\beta$ sensitized TL's cell cycle arresting effect in G0/G1 phase in HeLa cells suggesting TL-induced cell cycle arrest in HeLa cells is HSP90 $\beta$ dependent.

Previous studies have shown that TL exhibits high cytotoxicity in various cell lines $[36,37]$. We next investigated whether TL-triggered programmed cell death could be HSP90 $\beta$ related. Viability assay (Figure 4A) showed that knockdown of HSP90 $\beta$ potentiated TL cytotoxicity in HeLa cells as $\mathrm{IC}_{50}$ of TL in HSP90 $\beta$ knockdown cells (29.9 nM) was half of that in control siRNA transfected cells $(64.8 \mathrm{nM})$. Flow cytometry analysis (Figure 4B, upper panel) showed that $\mathrm{TL}$ treatment increased both early and late apoptotic cells

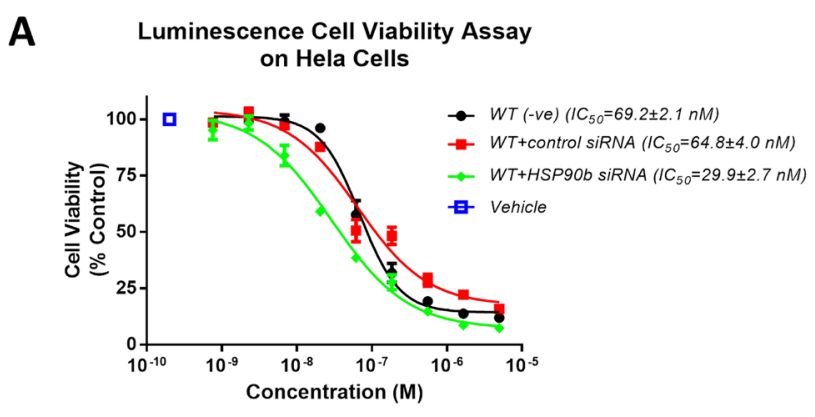

B
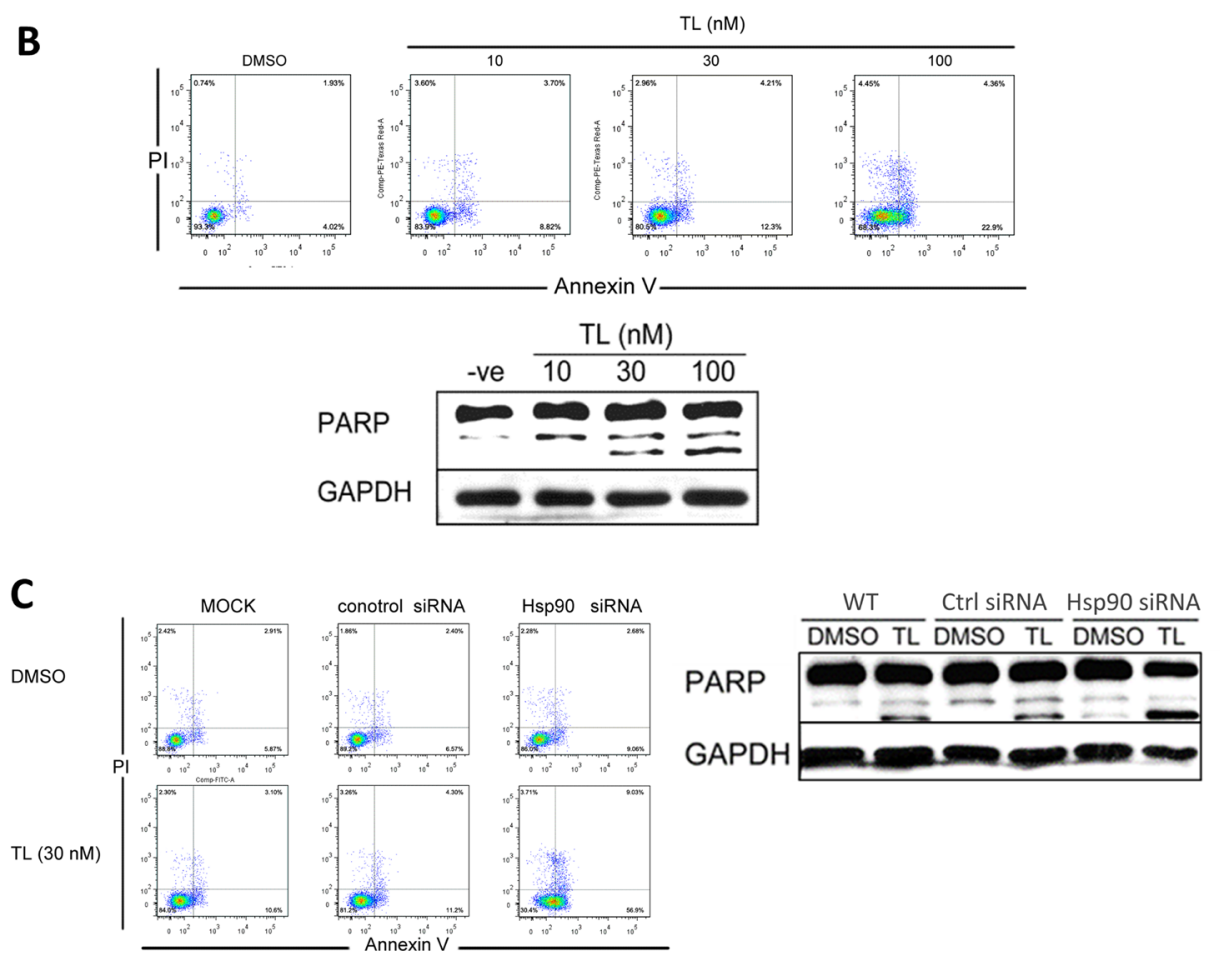

Figure 4: Triptolide triggers programmed cell death through HSP90ק. (A) TL exhibits cytotoxicity in HeLa cells. Luminescence cell proliferation assay was performed to determine cell viability of HeLa cells transfected with either control siRNA or HSP90 $\beta$ siRNA upon TL treatment for $24 \mathrm{hrs}$ in different concentrations. $\mathrm{IC}_{50}$ from three independent experiment was determined. Data are presented as mean $\pm \mathrm{SD}(n=3)$. (B) TL treatment triggers apoptosis in HeLa cells. Annexin V/PI analysis (upper) of apoptotic HeLa cells upon treatment of different concentrations of TL for $24 \mathrm{hrs}$. Western Blot analyses (lower) of cleavage PARP of HeLa cells upon 24 hrs' TL treatment. Representative image from three independent experiment was shown. (C) Knockdown of HSP90 $\beta$ sensitizes TL-triggered apoptosis in HeLa cells. Annexin V/PI analysis (left) of apoptotic cells and Western Blot (right) analyses of cleavage PARP of HeLa cells transfected with control siRNA or HSP90 $\beta$ siRNA in the presence and absence of TL for 24 hrs. Representative image from three independent experiment was shown. 
in HeLa cells in a dosage dependent manner (Early apoptotic cells: control 4.02\%, $10 \mathrm{nM}$ TL 8.82\%, $30 \mathrm{nM}$ TL $12.3 \%$ and $100 \mathrm{nM}$ TL 22.9\%; late apoptotic cells: control $1.93 \%, 10 \mathrm{nM}$ TL $3.7 \%, 30 \mathrm{nM}$ TL $4.21 \%$ and $100 \mathrm{nM}$ TL $4.36 \%$ ). WB analysis further showed that TL could induce PARP cleavage in a dosage dependent manner (Figure 4B, lower panel) which supported our findings on cellular apoptosis in flow cytometry analysis. Next, we setup to find out whether TL-induced apoptosis is HSP90 $\beta$ dependent. Flow cytometry analysis (Figure $4 \mathrm{C}$, left panel) revealed that knockdown of HSP90 $\beta$ could potentiate the induction of early and late apoptotic cells triggered by TL treatment when compared with TL-treated control siRNA transfected cells in which a slight induction of apoptotic cells was detected upon $30 \mathrm{nM}$ TL treatment. (Early apoptotic cells: control siRNA 6.57\%, TL+ control siRNA $11.2 \%$, TL+ HSP90siRNA 56.9\%; late apoptotic cells: control siRNA $2.4 \%$, TL+ control siRNA $4.3 \%$, TL + HSP90siRNA 9.03\%). Conformed to our results on cellular apoptosis, knockdown of HSP90 $\beta$ alone also increased cleaved PARP while TL treatment further increased PARP cleavage (Figure 4C, right panel). Taken together, silencing of HSP90 $\beta$ sensitizes and increases TL's toxicity indicating that TL-induced cytotoxicity is through inhibiting HSP90 $\beta$.

\section{TL induces site-specific phosphorylation of HSP90 $\beta$ in early phase}

So far, we have identified that TL inhibiting ATPase and chaperone activity and modifying the middle domain of HSP90 $\beta$ to disrupt its interaction with co-chaperone CDC37 are the long-term effects of the drug in mediating apoptosis. In asking whether any drug could have shorteffect on the regulation of HSP90 $\beta$ in relation to early apoptosis-trigger, we could not find such drug in the literature but serine 226 and serine 255 of HSP90 $\beta$ were reported to be co-regulated to be involved in cytochrome C-mediated apoptosome activation [38]. We then examined whether TL could have a short-term impact on the phosphorylation of serine 255 of HSP90 $\beta$. Timecourse WB analysis (Figure 5A) showed that TL treatment of HeLa cells led to rapid phosphorylation of HSP90 $\beta$ within 5 minutes, then the induction slowly diminished after 30 minutes. In contrast, although CEL shares some similar long-term inhibition mechanisms of HSP90 $\beta$ as TL does, it did not induce the phosphorylation of HSP90 $\beta$ in the same manner as TL. Phosphorylation of serine 226 and 255 has been identified to facilitate apoptosome formation, a prerequisite for cellular apoptosis [38]. We then examined other early apoptotic markers, and cleaved caspase-9/3 is considered apoptotic marker for cells committed to programmed cell death. Triggered by the HSP90 $\beta$ phosphorylation induction, WB analysis showed that TL treatment caused a marked increase in the cleaved caspase-9 levels two hours upon treatment. Due to the lack of HSP90 $\beta$ phosphorylation induction, only marginal increase in the cleaved caspase- 9 was observed four to six hours after CEL treatment (Figure 5B). Activated caspase- 9 subsequently cleaves procaspase- 3 to the activated form. We then examined the effects of TL on caspase- 3 activity, the immediate downstream target of apoptosome. Due to the HSP90 $\beta$ phosphorylation induction and subsequent cleavage of caspase-9, TL induced caspase- 3 activity significantly in HeLa cells one to two hour post treatment while caspase-3 activity was significantly and dramatically increased 15 hours post treatment, implying a bi-phasic activation of caspase-3 by TL (Figure 5C). As a result of the lack of HSP90 $\beta$ phosphorylation induction, CEL and WA only exhibited mono-phasic and modest activation of caspase- 3 activity within 15 hours post treatment and the activation only started to rise after 24 hours post treatment. To further examine TL-induced early apoptosome activation through phosphorylation on HSP90 $\beta$, HeLa cells were transfected with different HSP90 $\beta$ phosphorylation mutants (S226/255A and S226/255E) and tested for caspase-3 activity in the first 15 hours, a point where TL induced the highest activation of caspase- 3 activity. Transfection of HeLa cells with HSP90 $\beta^{\mathrm{S} 226 / 255 \mathrm{~A}}$ significantly delayed TL-induced caspase-3 early activation while transfection of HSP90 $\beta^{\mathrm{WT}}$ and HSP90 $\beta^{\mathrm{S} 226 / 255 \mathrm{E}}$ did not significantly affect the activation of caspase- 3 in the early phase (Figure 4D). Moreover, cells transfected with phosphorylationmimicking mutant also potentiated the activation when compared to wild type. Flow cytometry analysis (Figure $5 \mathrm{E})$ revealed that TL increased early apoptotic cells as early as 2 hours post treatment (from negative control: $4.05 \%$ to $2 \mathrm{H}: 5.92 \%$ ) and apoptotic cell population increased afterwards (6H: 7.25\%; 18H: 14.84\%). In contrast, CEL could not increase percentages of apoptotic cells until 18 hours post treatment (from negative control: $4.05 \%$; $2 \mathrm{H}: 4.17 \%$; $6 \mathrm{H}: 4.51 \%$ to $18 \mathrm{H}: 13.71 \%$ ), consistent with the results on the caspase- 3 activity assay. To conclude, TL exhibits a distinct property that is different from other HSP90 $\beta$ inhibitors by triggering phosphorylation of HSP90 $\beta$ and subsequent activations in the early phase of drug treatment.

\section{DISCUSSION}

HSP90 $\beta$ regulates multiple cellular pathways along with its co-chaperones which allows HSP90 $\beta$ appeared to be a primer target for drug development. Most HSP90 $\beta$ inhibitors shutdown HSP90 $\beta$ ATPase activity by targeting the ATP binding pocket of HSP90 $\beta$ at the N-terminal or the putative ATP binding site at the C-terminal. For instance, in two independent studies, Sun's group identified both CEL and WA bind to cysteine rich C-terminal of HSP90 $\beta$ $[39,40]$. Although cysteine is one of the less abundant naturally occurring amino acids in proteins, cysteines especially those exposed on protein surface have often 
been found to crucial to protein function. Cysteine can impact diverse functions ranging from regulating proteinprotein interaction to catalyzing enzymatic reaction, and reactive cysteines of a number of specific proteins become targets for drug development. A recent study revealed reactive cysteines on HSP90 $\beta$ through quantitative profiling under a chemical proteomics approach [41] and reported that cysteines 366 and 590 were the top two reactive cysteines among all other reactive cysteines identified in HSP90ß.

The chaperone activity of HSP90 $\beta$ is predominantly regulated by its ATPase activity. Abolishing the ATPase

A

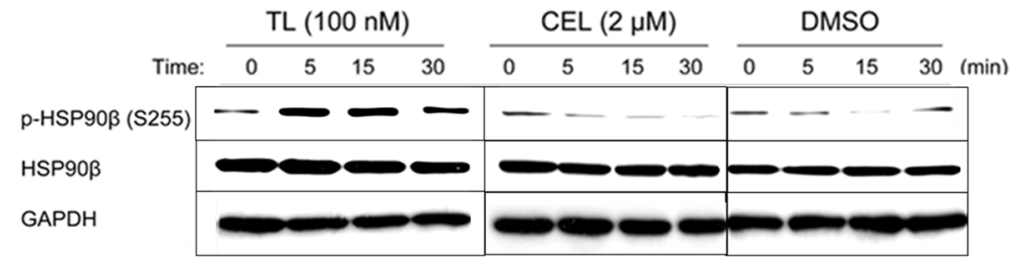

B

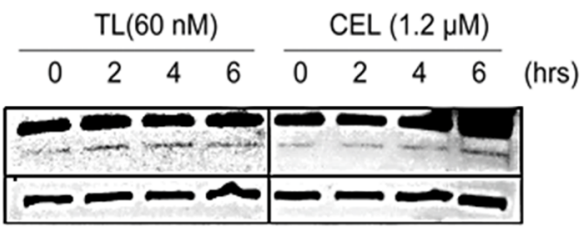

C

D
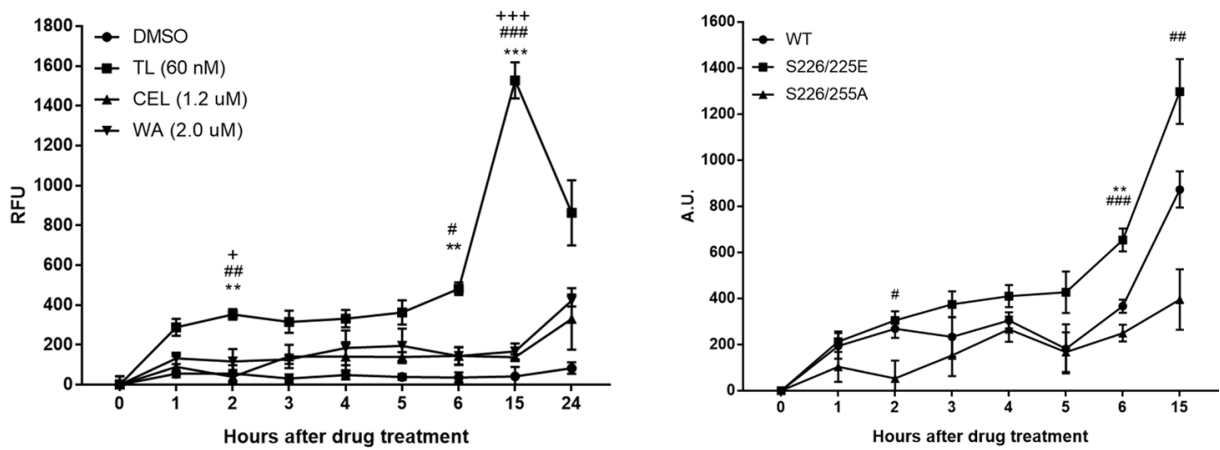

$\mathbf{E}$

Hours after drug treatment
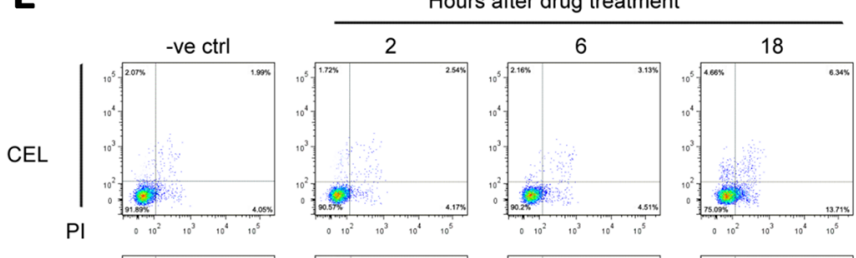

TL
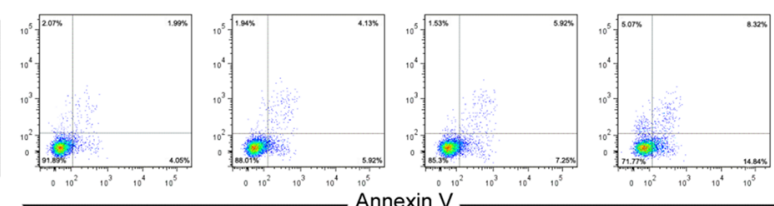

Figure 5: Phosphorylation of HSP90 $\beta$ is induced by TL in early phase. (A) TL induces site-specific phosphorylation of HSP90 $\beta$ within 5 minutes of drug treatment. Western blot analysis of phosphorylation of HSP90 $\beta$ in HeLa cells treated with TL and CEL for 0, 5, 15 and $30 \mathrm{~min}$. Representative image from three independent experiment was shown. (B) Western blot analysis of caspase-9 in TL/CELtreated HeLa cells for 0, 2, 4 and 6 hrs. Representative image from three independent experiment was shown. (C) TL activates caspase-3 activity in the early phase. Caspase- 3 activity was detected for HeLa cells upon TL, CEL and WA treatment over a time course from 0 to $24 \mathrm{hrs}$. At indicated time-points, cell lysate was prepared and incubated with assay buffer for at $37^{\circ} \mathrm{C}$ for $1 \mathrm{hr}$. Fluorescence was detected with an excitation at $405 \mathrm{nM}$ and emission at $465 \mathrm{nM} .{ }^{* *} P<0.01 ;{ }^{* * *} P<0.001$ DMSO versus TL. ${ }^{\#} P<0.01 ;{ }^{\# \#} P<0.001$ TL versus CEL. ${ }^{+} P<0.05 ;{ }^{++} P<0.001$ TL versus WA. Data are presented as mean $\pm \mathrm{SD}(n=3)$. (D) Hypophosphorylation of HSP90 $\beta$ prevents TL mediated early activation of caspase-3 in HeLa cells. Caspase- 3 activity assay was performed in HeLa cells transfected with different phosphorylation mutants of HSP90 $\beta$. Data are presented as mean $\pm \mathrm{SD}(n=3) .{ }^{* *} P<0.01 \mathrm{WT}$ versus $\mathrm{S} 226 / 225 \mathrm{E}$. ${ }^{\#} P<0.05$; ${ }^{\#} P<0.01$; ${ }^{\# \#} P$ $<0.001 \mathrm{~S} 226 / 225 \mathrm{E}$ versus S226/225A. (E) TL induces cell apoptosis in a shorter time-frame when compared to those upon CEL treatment. Annexin V/PI analysis of apoptotic HeLa cells upon TL and CEL for 2, 6 and $18 \mathrm{hrs}$. 
activity of HSP90 $\beta$ adversely affects its dimerization of $\mathrm{N}$-terminal domain resulting in loss of chaperone activity. Kupchan and coworkers [42] reported that TL modifies cysteine through alkylation of an epoxide group. In our current study, TL exhibits inhibitory effect on the ATPase activity of HSP90 $\beta$ as well as the ATP binding which is distinct from CEL which only inhibits ATPase activity. ATPase activity assay and ATP binding assay conducted on two HSP90 $\beta$ cysteine mutants revealed that TL's inhibition of ATPase activity is through preventing ATP binding and could not rule out the possible involvement of cys590 in TL-mediated inhibition. Martínez-Ruiz A and colleagues previously identified cysteine 590 on HSP90 $\beta$ or cysteine 597 on HSP90 $\alpha 1$ being susceptible to nitrosylation [43], and nitrosylation on such cysteines decreases ATPase activity of HSP90 $\beta$. Recent study conducted by Retzlaff suggested that ATPase activity of HSP90 $\beta$ is regulated by a C-terminal regulatory site through influencing its C-terminal dimerization [44]. Switching Alanine 577 in yHSP90 (counterpart of cysteine 590 in HSP90 $\beta$ ) to Isoleucine led to stabilization of intra-molecular $\beta$-sheet at C-terminal of HSP90 $\beta$ while mutation of alanine 577 into asparagine increased C-terminal dissociation constant resulting a less stable HSP90 $\beta$ dimer. Potentially, modification of cysteine 590 by TL could possibly have the same effect as a $\beta$-sheet destabilizer at HSP90 $\beta$ $\mathrm{C}$-terminal resulting in a decrease of ATPase activity. Furthermore, TL treatment suppresses HSP90 $\beta$ chaperone activity which was verified by luciferase refolding assay which is a likely consequence of inhibition of its ATPase activity. Our findings provide evidence for HSP90 $\beta$ 's ATPase inhibition via ATP binding and subsequently inhibiting its chaperone activity of this cysteine reacting HSP90 $\beta$ inhibitor.

We then examined the downstream events of HSP90 $\beta$ chaperone inhibition. We found that TL decreases client protein levels of Raf-1 without altering its expression in HeLa cells. Study on identification of XPB as one of the targets of TL [34] suggested that TL has a universal transcriptional suppression effect through inhibiting RNA polymerase TFIIH activity. Surprisingly, TL does not specifically downregulate the transcription of HSP90 $\beta$ client proteins in our study. Besides, our data suggests that such suppression has no prominent effect on the HSP90 $\beta$ chaperone machinery. Our data further showed that TL has no significant change on expression levels at both mRNA and protein levels of HSP90 $\beta$, its client proteins and co-chaperone such as IKK or CDC37 respectively.

CDC37 is a co-chaperone of HSP90 $\beta$ responsible for recruiting protein kinase clients of HSP90 $\beta$-CDC37 complexes. Over the past decade, evidences including X-ray crystallography suggest that HSP90 $\beta$ interacts with CDC37 at its N-terminal domain [45]. Emerging evidences reveal CDC37 forms complex with HSP90 $\beta$ at both N-terminus and middle domains otherwise [18]. As both WA and CEL disrupt the HSP90 $\beta$-CDC37 complexes through the N-terminal domain $[40,46]$, there is a growing interest to examine whether any drug could disrupts the HSP90 $\beta-C D C 37$ complexes through the middle domain. Nevertheless, dissociation of HSP90 $\beta$-CDC37 complexes results in degradation of premature protein kinase clients. Pulldown assay using various HSP90 $\beta$ mutants and recombinant $\mathrm{CDC} 37$ revealed that mutation of cysteine 366 has no effect on HSP90 $\beta$-CDC37 interaction itself while such mutation prevents TL-mediated destabilization of the HSP90 $\beta$-CDC37 complexes. This observation is consistent with the fact that besides HSP90 $\beta$ interfaces with $\mathrm{CDC} 37$ at its N-terminal domain, a change in the middle domain could have an effect on the interaction. Our data showed that TL hinders the interaction between HSP90 $\beta$ and CDC37 by altering HSP90 $\beta$ microenvironment in the middle domain containing Cys366. Furthermore, we also confirmed that incubation of TL with CDC37 alone would have no effect on the interaction between HSP90 $\beta$ and CDC37, indicating that the disruption of the interaction mediated by TL is dependent on HSP90 $\beta$.

Cell cycle progression is tightly fine-tuned by a group of CDCs and CDKs on discrete checking points inside cells. It has been reported that TL alters cell cycle profiling in a cell type dependent manner. It can be further explained by TL's widely different $\mathrm{IC}_{50}$ values and distinct cellular targets in different cell types. Dysfunction of HSP90 $\beta$ chaperone machinery by TL results in G1/ G0 cell cycle arrest in HeLa cells. The consequence of the disruption of HSP90 $\beta$-CDC37 complexes by TL is reflected by the decrease in client protein kinase CDK4 protein levels as well as the phosphorylation of $\mathrm{Rb}$. Knockdown of HSP90 $\beta$ significantly sensitizes the cell cycle arrest effect triggered by TL thereby indicating that induction of cell cycle arrest by TL in HeLa cells is HSP90 $\beta$-dependent. It is known that HSP90 $\beta$ machinery is responsible for maintaining the conformation, stability and function of many oncogenic client proteins in cancer cells $[7,47]$. In addition to cell cycle arrest-induced apoptosis, degradation of HSP90 $\beta$ pro-survival client proteins triggers programmed cell death. There exists a high correlation between the abundance of HSP90 $\beta$ and TL induced-apoptosis. Knockdown of HSP90 $\beta$ dramatically enhanced TL's cytotoxicity verified by various apoptotic markers. Silencing of HSP90 $\beta$ caused an approximately 2-fold decrease of TL's $\mathrm{IC}_{50}$ in HeLa cells. It is possible that TL exerts most of its cytotoxic effect by inhibiting HSP90 $\beta$; therefore, silencing of HSP90 $\beta$ is essentially the same as inhibiting HSP90 $\beta$ by TL. As a result, no drastic fold increase in potency was observed, and the 2-fold decrease was due to more silenced HSP90 $\beta$ as compared to TL-inhibited HSP90 $\beta$.

In our study, silencing of HSP90 $\beta$, expressed in higher abundance in cancer cells, shifts the $\mathrm{IC}_{50}$ to the left in HeLa cells. This result demonstrates that HSP90 $\beta$ mediates 
TL's effect as it takes lower effective concentration of TL to inhibit HSP90 $\beta$ in lower abundance in HSP90 $\beta$ knockdown cells. As shown in Figure 4A, at the lowest concentration of TL whereas the effect of TL is negligible, silencing of HSP90 $\beta$ has no effect on the cellular proliferation. This concludes that a $60 \%$ knockdown of HSP90 $\beta$ is probably sufficient to maintain cellular viability. The difference observed at higher concentration of TL is a direct reflection of TL-mediated inhibition of HSP90 $\beta$. Although the molecular concentration of HSP90 $\beta$ in cancer cells is in $\mu \mathrm{M}$ range, TL, a nM drug, is only targeting functional HSP90 $\beta$ to exhibit its effect. Taken together, our study showed that HSP90 $\beta$ is potentially one of the few major targets of TL. TL's inhibition of HSP90 $\beta$ is upstream and transient making HSP90 $\beta$ a cancer selective and desirable target.

Kurokawa and colleagues reported that phosphorylation on serine 226 and 255 on HSP90 $\beta$ impedes inhibitory effect of HSP90 $\beta$ in relation to apoptosome formation [38]. Apart from the long-term effect of TL, CEL and WA on the inhibition of HSP90 $\beta$ to drive apoptosis, activation of caspase- 3 activity, the immediate target of apoptosome, suggests a bi-phasic activation of caspase- 3 triggered by TL. However, CEL and WA, in consistent with their long term effects on apoptotic induction, only exhibit a monophasic activation of caspase- 3 in the long duration of drug treatment. Our results further indicate that only TL could induce caspase- 3 activation at 1-2 hours after treatment which closely resembles the activation of caspase- 3 by WT and phosphorylation-mimicking mutant of HSP90 $\beta$ in the first 1-2 hours of the early treatment. This early activation was not observed with the phosphorylationblocking mutant could only suggest that the site-specific phosphorylation is responsible for the early phase but would not significantly affect the late phase activation of caspase- 3 during the drug treatment. The observation that TL induces caspase- 3 activation in the presence of WT HSP90 $\beta$ to a similar level that is the same as the phosphorylationmimicking mutant strongly suggests that TL-mediated sitespecific phosphorylation of HSP90 $\beta$ is responsible for the early activation of caspase-3. Flow cytometry data further confirmed that HeLa cells exhibit a much faster response to TL than CEL to induce early apoptotic cells. We first report a drug that is capable of inhibiting HSP90 $\beta$ by inducing its site-specific phosphorylation to trigger early apoptotic response.

In conclusion, we demonstrate that TL is a novel middle domain HSP90 $\beta$ inhibitor with a bi-phasic multimechanistic inhibition of HSP90 $\beta$ working in concert to trigger programmed cell death in cancer cells. TL inhibits ATPase activity of HSP90 $\beta$ by preventing ATP binding and decreasing overall HSP90 $\beta$ chaperone activity. In the meanwhile, TL disrupts HSP90 $\beta$-CDC37 interaction through the middle domain cys366 resulting in kinase client protein degradation and cell cycle arrest. In contrast to other HSP90 $\beta$ inhibitors, TL exhibits a unique biphasic, in both short and long term, inhibition of HSP90 $\beta$ activity by inducing site-specific phosphorylation which offers a faster and more effective inhibition of HSP90 $\beta$.

\section{MATERIALS AND METHODS}

\section{Cells and reagents}

Dulbecco's Modified Eagle Medium (DMEM), Fetal Bovine Serum (FBS), Penicillin/streptomycin $(\mathrm{P} / \mathrm{S})$ for cell culture, blocking solution for Western blot, MANT-ADP for ATPase binding assay, Opti-MEM medium, siRNA (HSP90 $\beta$, scramble), lipofectamin 2000, lipofectamine RNAi Max for transfection, qRT-PCR kit were obtained from Life Technology. RIPA lysis buffer, ECL were purchased from Thermo; protease inhibitors and phosphor-stop were acquired from Roche. Streptactin superflow plus were purchased from Qiagen. Bradford protein assay kit was purchased from Bio-rad. High Throughput Colorimetric ATPase Assays kit were from Innova Biosciences. Caspase-3 activity assay kit was purchased from Cell Signaling. Apoptosis detection kit was purchased from BD. For antibodies, Raf-1, IKK1/2, HSP90 $\beta$, p-HSP90ß, HSP70, CDC37, PPIA, p-MEK, MEK, p-ERK, ERK, GAPDH, PARP and Ub antibodies were purchased from Santa Cruz; Anti-flag antibodies was from Sigma; CDK4, p-Rb, Caspase-9, eEF2 and StrepHRP antibodies were from Cell Signaling. All chemicals not listed above were purchased from Sigma-Aldrich.

\section{Protein expression and purification}

BL21(DE3)_pET52b_HSP90 $\beta$ was inoculated in auto-induction medium and cultured for overnight at $1: 200$ ratio at $37^{\circ} \mathrm{C}$. Bacteria culture was then incubated at $37^{\circ} \mathrm{C}$ until $\mathrm{OD}_{600}$ reached around 0.8 and subsequently further cultured for 18 hours at $18^{\circ} \mathrm{C}$. Cells were lyzed by sonication in lysis buffer and centrifuged at $16,000 \mathrm{~g}$ for 20 minutes to remove cell debris. Supernatant were collected and passed through strep-tag column. Elutes were quantified and subjected to precision enzyme digestion to remove strep tag. Protein were further purified by passing through Q-column and followed by streptag column. In the last step, proteins were desalted and concentrated by $10 \mathrm{~K}$ filtering units.

HEK-293T cells were cultured in DMEM and transfected with plasmids with PEI-HCl in Opti-MEM medium. Cells were harvest 48 hours after transfection and lyzed. Subsequently, strep-beads were incubated with cell lysate at $4^{\circ} \mathrm{C}$. After washed by PBST for three times, strep-beads bound proteins were eluted by elution buffer (PBS with $2 \mathrm{mM}$ desthiobiotin).

\section{ATPase assay}

ATPase activity assay was performed using High Throughput Colorimetric ATPase Assays kit. Bacterial 
expressed recombinant HSP90 $\beta$ proteins (WT and different mutants) were incubated with TL and different inhibitors at $4^{\circ} \mathrm{C}$ for 3 hours and then added to reaction mixture according to the manufacturer's protocol. After incubated for additional 1 hour at $37^{\circ} \mathrm{C}$, absorbance at 650 $\mathrm{nM}$ were detected and analyzed using Beckman Coulter plate-reader.

\section{MANT-ADP releasing assay}

Recombinant HSP90 $\beta$ (WT and different mutants) were incubated with TL and different inhibitors for 3 hours $4^{\circ} \mathrm{C}$. MANT-ADP was then added to the reaction mixture. The reaction mixture was incubated for additional 1 hour at $37^{\circ} \mathrm{C}$ and analyzed using Beckman Coulter plate-reader with excitation at $370 \mathrm{nM}$ and emission at $465 \mathrm{nM}$.

\section{Ni-NTA pulldown assay}

Recombinant HSP90 $\beta$ protein was preincubated with TL and different inhibitors at $4^{\circ} \mathrm{C}$ for 3 hours in incubation buffer $(20 \mathrm{mM}$ Tris, $150 \mathrm{mM} \mathrm{NaCl}, 5$ $\mathrm{mM} \mathrm{MgCl}, 1 \%$ Triton-X-100, $10 \%$ glycerol, $\mathrm{pH}=7.5)$. In the meanwhile, His-tagged CDC37 was incubated Ni-NTA beads at $4^{\circ} \mathrm{C}$ for 1 hour. His-CDC37-Ni-NTA complex was then mixed with drug-treated HSP90 $\beta$ for additional 3 hours. Ni-NTA beads were washed with the incubation buffer, and then bound proteins were eluted by boiling in sample buffer. Elutes were then subjected to immunoblot analysis.

\section{Streptavidin pulldown assay}

Cells were washed with ice-cold PBS and harvested in a immunoprecipitation (IP) lysis buffer $(50 \mathrm{mM}$ HEPES, $2 \mathrm{mM} \mathrm{MgCl}_{2}, 150 \mathrm{mM} \mathrm{NaCl}, 20 \%$ glycerol, $0.5 \%$ $\mathrm{NP}-40, \mathrm{pH}=7.5$ with protease inhibitor cocktail). Lysates were centrifuged at $13,000 \mathrm{~g}$ for $10 \mathrm{~min}$. Supernatant was collected and incubated with streptavidin overnight at $4^{\circ} \mathrm{C}$. Beads were then washed with ice-cold lysis buffer and bound proteins were eluted by boiling in sample buffer. Elutes were then subject to immunoblot analysis.

\section{Immunoprecipitation assay}

Cells upon treatment were washed with ice-cold PBS and harvested in an immunoprecipitation (IP) lysis buffer (50 mM HEPES, $2 \mathrm{mM} \mathrm{MgCl}{ }_{2}, 150 \mathrm{mM} \mathrm{NaCl}, 20 \%$ glycerol, $0.5 \% \mathrm{NP}-40, \mathrm{pH}=7.5$ with protease inhibitor cocktail). Lysates were centrifuged at $13,000 \mathrm{~g}$ for $10 \mathrm{~min}$. The supernatant was collected and then incubated with primary antibodies overnight at $4{ }^{\circ} \mathrm{C}$. Protein A/G agarose beads were then added to each sample and incubated at $4^{\circ} \mathrm{C}$ for 2 hours. Beads were then washed three times with ice-cold lysis buffer and bound proteins were eluted by boiling in sample buffer. Elutes were then subject to immunoblot analysis.

\section{Western blotting}

Cells were lysed in ice-cold RIPA lysis buffer and protein samples were subjected to electrophoresis in $8-12 \%$ SDS-polyacrylamide gels. Proteins were then transferred to PVDF membrane, blocked with 5\% milk in TBST or blocking solution. Membrane was incubated with primary antibodies. After washing with TBST, blots were then probed with specific secondary antibodies linked to horseradish peroxidase (HRP). After washing with TBST, signals were then detected by chemoluminescence system.

\section{Transfection in HeLa cells}

Hela cells were seeded in 6-well plate and transfected. For HSP90 $\beta$ knockdown, cells were transfected with mixture of siRNA and Lipo-RNAi Max transfection reagent in opti-MEM. For transfection with HSP90 $\beta$ expression vectors, cells were transfected with mixture of plasmid and Lipofectamine 2000 in opti-MEM. Cells were then treated with TL and different inhibitors for 24 hours and subjected to biochemical analyses.

\section{Flow cytometry analysis on HeLa cell}

For PI-Annexin V staining, cells were washed by PBS and resuspended in Annexin $\mathrm{V}$ binding buffer with FITC Annexin V and propidium iodide solution. Cells were then incubated at room temperature for 15 minutes and subjected to flow cytometry analysis. For cell cycle analysis, cells were washed by PBS and resuspended in PI staining solution $(20 \mu \mathrm{g} / \mathrm{mL}$ propidium iodide, $0.5 \%$ RNase A, $0.05 \%$ triton-X-100 in PBS). Cells were then incubated for 15 minutes and then subjected to flow cytometry analysis.

\section{Luciferase refolding assay}

Luciferase was dissolved in protein buffer (25 $\mathrm{mM}$ Tris, $8 \mathrm{mM} \mathrm{MgSO}{ }_{4}, 0.1 \mathrm{mM}$ EDTA and $0.5 \mathrm{mg} / \mathrm{mL}$ BSA, $10 \%$ glycerol and $1 \%$ triton $\mathrm{X}-100, \mathrm{pH}=7.5$ ) to $0.5 \mathrm{mg} / \mathrm{mL}$. For heat denaturing, luciferase was heated at $41^{\circ} \mathrm{C}$ for $10 \mathrm{~min}$. The luciferase reaction master mix was prepared by mixing reaction buffer (100 mM Tris, $10 \mathrm{mM} \mathrm{Mg}(\mathrm{OAc})_{2}, 375 \mathrm{mM} \mathrm{KCl}, 15 \mathrm{mM}$ ATP, and $25 \mathrm{mM}$ creatine phosphate, $\mathrm{pH}=7.5$ ) with $\mathrm{CPK}$, heatdenatured native luciferase in deionized water. Drugs were dissolved in working buffer $(20 \mathrm{mM}$ Tris, $75 \mathrm{mM} \mathrm{KCl}, \mathrm{pH}$ $=7.5$ ), and then added to luciferase reaction master mix. Rabbit reticulocyte lysate was added to the mixture and the mixture was incubated at $4^{\circ} \mathrm{C}$ for 3 hours. Luciferase activity was measured by adding reaction mixture to luciferase assay buffer and incubated at room temperature for 5 minutes. Luminescence signal was measured with integration time of $400 \mathrm{~ms}$ on Beckman Coulter platereader. 


\section{Real-time PCR}

Total RNA was extracted from HeLa cells by RNA extraction kit. The quantitative real-time RT-PCR was performed using the Superscript III Platinum SYBR Green One Step qRT-PCR kit according to the protocols in Applied Biosystem PCR Detection System. Primers used for qRT-PCR were from PrimerBank (http://pga.mgh. harvard.edu/primerbank/) and the qRT-PCR results were normalized against GAPDH.

\section{Cell proliferation assay}

For cell proliferation assay, CellTiter-Glo ${ }^{\circledR}$ Reagent was added to cells upon treatment for cell lysis at room temperature. Cells were then incubated for 10 minutes, and luminescent signal was detected by Beckman Coulter plate-reader with $400 \mathrm{~ms}$ integration time.

\section{Caspase-3 activity assay}

Cells upon assay were washed with PBS and lyzed in cell lysis buffer. Cell lysate was then incubated with assay buffer for at $37^{\circ} \mathrm{C}$ for 1 hour in dark. Fluorescent signal was detected by Beckman Coulter plate-reader with an excitation at $405 \mathrm{nM}$ and emission at $465 \mathrm{nM}$.

\section{Statistical analysis}

All data were presented as mean \pm standard deviation (SD). Statistical significance among treatment groups were determined by Student's $T$-test and one-way analysis of variance (ANOVA). ${ }^{*} p<0.05 ;{ }^{* *} p<0.01^{* * *} ; p$ $<0.001$ indicate statistical significance.

\section{Abbreviations}

ADP: Adenosine diphosphate; ATP: Adenosine triphosphate; BME: 2-Mercaptoethanol; CDC: Cell division cycle; CDK: Cyclin-dependent kinase 4; CEL: Celastrol; Cys: Cysteine; DMEM: Dulbecco's Modified Eagle Medium; DMSO: Dimethyl sulfoxide; FACS: Fluorescence-activated cell sorting; GAPDH: Glyceraldehyde 3-phosphate dehydrogenase; HOP: HSP70-HSP90 organizing protein; HRP: Horseradish peroxidase; HSF-1: Heat shock factor-1; HSP: Heat Shock Protein; $\mathrm{IC}_{50}$ : Half Maximal Inhibitory Concentration; MANT-ADP: $\quad$ (2'-(or-3')-O-(N-Methylanthraniloyl) Adenosine 5'-Diphosphate; NOV: Novobiocin; PAGE: Polyacrylamide gel electrophoresis; PBS: Phosphate buffered saline; PEI: Polyethylenimine; PI: Propidium iodine; RAD: Radicicol; Rb: retinoblastoma protein; RTPCR: real-time polymerase chain reaction; SDS: Sodium dodecyl sulfate; siRNA: small interfering RNA; Strep: streptactin; TL: Triptolide; TPR: tetratricopeptide repeat; TwHf: Tripterygium wilfordii Hook f; Ub: ubiquitination;
WA: Withaferin A; WT: wild type; XPB: Xeroderma Pigmentosum B.

\section{Author contributions}

Conception and design: F. Zhang, R. Wong, Development of methodology: F. Zhang, Acquisition of data: F. Zhang, Analysis and interpretation of data: F. Zhang, D. Ho, R. Wong, Writing, review, and/or revision of the manuscript: F. Zhang, D. Ho, R. Wong.

\section{ACKNOWLEDGMENTS}

The authors thank Drs. Kok Hei Yau and Lin Zhu for technical assistance and critical discussion, Dr. Dan Yang for financial assistance and Dr. Hong Lok Lung for critical reading of the manuscript.

\section{CONFLICTS OF INTEREST}

All authors have no potential conflicts of interests.

\section{FUNDING}

For grant support, this work was supported by the HKBU SDF 15-1012-P04, HKBU FRG2/16-17/061, RGC General Research Fund HKBU12143316.

\section{REFERENCES}

1. Hartl FU, Bracher A, Hayer-Hartl M. Molecular chaperones in protein folding and proteostasis. Nature. 2011; 475:32432. https://doi.org/10.1038/nature10317.

2. Ciocca DR, Calderwood SK. Heat shock proteins in cancer: diagnostic, prognostic, predictive, and treatment implications. Cell Stress Chaperones. 2005; 10:86-103.

3. Pratt WB, Toft DO. Regulation of signaling protein function and trafficking by the hsp90/hsp70-based chaperone machinery. Exp Biol Med (Maywood). 2003; 228:111-33.

4. Jackson SE. Hsp90: structure and function. Top Curr Chem. 2013; 328:155-240. https://doi.org/10.1007/128_2012_356.

5. Krukenberg KA, Street TO, Lavery LA, Agard DA. Conformational dynamics of the molecular chaperone Hsp90. Q Rev Biophys. 2011; 44:229-55. https://doi. org/10.1017/s0033583510000314.

6. Chadli A, Bruinsma ES, Stensgard B, Toft D. Analysis of Hsp90 cochaperone interactions reveals a novel mechanism for TPR protein recognition. Biochemistry. 2008; 47:28507. https://doi.org/10.1021/bi7023332.

7. Riggs DL, Cox MB, Cheung-Flynn J, Prapapanich V, Carrigan PE, Smith DF. Functional specificity of cochaperone interactions with Hsp90 client proteins. Crit Rev Biochem Mol Biol. 2004; 39:279-95. https://doi. org/10.1080/10409230490892513. 
8. Xu W, Neckers L. Targeting the molecular chaperone heat shock protein 90 provides a multifaceted effect on diverse cell signaling pathways of cancer cells. Clin Cancer Res. 2007; 13:1625-9. https://doi.org/10.1158/1078-0432.ccr-06-2966.

9. Moulick K, Ahn JH, Zong H, Rodina A, Cerchietti L, Gomes DaGama EM, Caldas-Lopes E, Beebe K, Perna F, Hatzi K, Vu LP, Zhao X, Zatorska D, et al. Affinity-based proteomics reveal cancer-specific networks coordinated by Hsp90. Nat Chem Biol. 2011; 7:818-26. https://doi. org/10.1038/nchembio.670.

10. Zhang S, Sun Y, Yuan Z, Li Y, Li X, Gong Z, Peng Y. Heat shock protein 90beta inhibits apoptosis of intestinal epithelial cells induced by hypoxia through stabilizing phosphorylated Akt. BMB Rep. 2013; 46:47-52.

11. Jhaveri K, Taldone T, Modi S, Chiosis G. Advances in the clinical development of heat shock protein 90 (Hsp90) inhibitors in cancers. Biochim Biophys Acta. 2012; 1823:742-55. https://doi.org/10.1016/j. bbamcr.2011.10.008

12. Li Y, Zhang T, Schwartz SJ, Sun D. New developments in Hsp90 inhibitors as anti-cancer therapeutics: mechanisms, clinical perspective and more potential. Drug Resist Updat. 2009; 12:17-27. https://doi.org/10.1016/j.drup.2008.12.002.

13. Xiao L, Lu X, Ruden DM. Effectiveness of hsp90 inhibitors as anti-cancer drugs. Mini Rev Med Chem. 2006; 6:1137-43.

14. Basso AD, Solit DB, Chiosis G, Giri B, Tsichlis P, Rosen N. Akt forms an intracellular complex with heat shock protein 90 (Hsp90) and Cdc37 and is destabilized by inhibitors of Hsp90 function. J Biol Chem. 2002; 277:39858-66. https:// doi.org/10.1074/jbc.M206322200.

15. Miyata Y, Ikawa Y, Shibuya M, Nishida E. Specific association of a set of molecular chaperones including HSP90 and Cdc37 with MOK, a member of the mitogenactivated protein kinase superfamily. J Biol Chem. 2001; 276:21841-8. https://doi.org/10.1074/jbc.M010944200.

16. Walton-Diaz A, Khan S, Bourboulia D, Trepel JB, Neckers L, Mollapour M. Contributions of co-chaperones and post-translational modifications towards Hsp90 drug sensitivity. Future Med Chem. 2013; 5:1059-71. https:// doi.org/10.4155/fmc.13.88.

17. Richter K, Buchner J. hsp90: twist and fold. Cell. 2006; 127:251-3. https://doi.org/10.1016/j.cell.2006.10.004.

18. Eckl JM, Rutz DA, Haslbeck V, Zierer BK, Reinstein J, Richter K. Cdc37 (cell division cycle 37) restricts Hsp90 (heat shock protein 90) motility by interaction with N-terminal and middle domain binding sites. J Biol Chem. 2013; 288:16032-42. https://doi.org/10.1074/jbc. M112.439257.

19. Zhang T, Li Y, Yu Y, Zou P, Jiang Y, Sun D. Characterization of celastrol to inhibit hsp90 and cdc37 interaction. J Biol Chem. 2009; 284:35381-9. https://doi.org/10.1074/jbc. M109.051532.

20. Yu Y, Hamza A, Zhang T, Gu M, Zou P, Newman B, Li Y, Gunatilaka AA, Zhan CG, Sun D. Withaferin A targets heat shock protein 90 in pancreatic cancer cells. Biochem Pharmacol. 2010; 79:542-51. https://doi.org/10.1016/j. bcp.2009.09.017.

21. Lin SF, Lin JD, Hsueh C, Chou TC, Yeh CN, Chen MH, Wong RJ. Efficacy of an HSP90 inhibitor, ganetespib, in preclinical thyroid cancer models. Oncotarget. 2017; 8:41294-304. https://doi.org/10.18632/oncotarget.17180.

22. Shrestha L, Patel HJ, Chiosis G. Chemical Tools to Investigate Mechanisms Associated with HSP90 and HSP70 in Disease. Cell Chem Biol. 2016; 23:158-72. https://doi. org/10.1016/j.chembiol.2015.12.006.

23. Liu Q. Triptolide and its expanding multiple pharmacological functions. Int Immunopharmacol. 2011; 11:377-83. https://doi.org/10.1016/j.intimp.2011.01.012.

24. Carter BZ, Mak DH, Schober WD, Dietrich MF, Pinilla C, Vassilev LT, Reed JC, Andreeff M. Triptolide sensitizes AML cells to TRAIL-induced apoptosis via decrease of XIAP and p53-mediated increase of DR5. Blood. 2008; 111:3742-50. https://doi.org/10.1182/ blood-2007-05-091504.

25. Jiang XH, Wong BC, Lin MC, Zhu GH, Kung HF, Jiang $\mathrm{SH}$, Yang D, Lam SK. Functional p53 is required for triptolide-induced apoptosis and AP-1 and nuclear factorkappaB activation in gastric cancer cells. Oncogene. 2001; 20:8009-18. https://doi.org/10.1038/sj.onc.1204981.

26. Li W, Liu Y, Li XX, Yu Y, Wu JJ, Wang Q, Huo H, Wang LM, Yang L. MAPKs are not involved in triptolide-induced cell growth inhibition and apoptosis in prostate cancer cell lines with different p53 status. Planta Med. 2011; 77:27-31. https://doi.org/10.1055/s-0030-1250076.

27. Phillips PA, Dudeja V, McCarroll JA, Borja-Cacho D, Dawra RK, Grizzle WE, Vickers SM, Saluja AK. Triptolide induces pancreatic cancer cell death via inhibition of heat shock protein 70. Cancer Res. 2007; 67:9407-16. https:// doi.org/10.1158/0008-5472.can-07-1077.

28. He QL, Titov DV, Li J, Tan M, Ye Z, Zhao Y, Romo D, Liu JO. Covalent modification of a cysteine residue in the XPB subunit of the general transcription factor TFIIH through single epoxide cleavage of the transcription inhibitor triptolide. Angew Chem Int Ed Engl. 2015; 54:1859-63. https://doi.org/10.1002/anie.201408817.

29. Vaughan CK, Piper PW, Pearl LH, Prodromou C. A common conformationally coupled ATPase mechanism for yeast and human cytoplasmic HSP90s. FEBS J. 2009; 276:199-209. https://doi.org/10.1111/j.1742-4658.2008.06773.x.

30. Martínez-Ruiz A, Villanueva L, González de Orduña C, López-Ferrer D, Higueras MA, Tarín C, RodríguezCrespo I, Vázquez J, Lamas S. S-nitrosylation of Hsp90 promotes the inhibition of its ATPase and endothelial nitric oxide synthase regulatory activities. Proc Natl Acad Sci USA. 2005; 102:8525-30. https://doi.org/10.1073/ pnas.0407294102.

31. Galam L, Hadden MK, Ma Z, Ye QZ, Yun BG, Blagg BS, Matts RL. High-throughput assay for the identification of 
Hsp90 inhibitors based on Hsp90-dependent refolding of firefly luciferase. Bioorg Med Chem. 2007; 15:1939-46. https://doi.org/10.1016/j.bmc.2007.01.004.

32. Vispe S, DeVries L, Creancier L, Besse J, Breand S, Hobson DJ, Svejstrup JQ, Annereau JP, Cussac D, Dumontet C, Guilbaud N, Barret JM, Bailly C. Triptolide is an inhibitor of RNA polymerase I and II-dependent transcription leading predominantly to down-regulation of short-lived mRNA. Mol Cancer Ther. 2009; 8:2780-90. https://doi. org/10.1158/1535-7163.mct-09-0549.

33. Manzo SG, Zhou ZL, Wang YQ, Marinello J, He JX, Li YC, Ding J, Capranico G, Miao ZH. Natural product triptolide mediates cancer cell death by triggering CDK7-dependent degradation of RNA polymerase II. Cancer Res. 2012; 72:5363-73. https://doi.org/10.1158/0008-5472.can-121006.

34. Titov DV, Gilman B, He QL, Bhat S, Low WK, Dang Y, Smeaton M, Demain AL, Miller PS, Kugel JF, Goodrich JA, Liu JO. XPB, a subunit of TFIIH, is a target of the natural product triptolide. Nat Chem Biol. 2011; 7:182-88.

35. Grammatikakis N, Lin JH, Grammatikakis A, Tsichlis PN, Cochran BH. p50(cdc37) acting in concert with Hsp90 is required for Raf-1 function. Mol Cell Biol. 1999; 19:1661-72.

36. Wu J, Li QQ, Zhou H, Lu Y, Li JM, Ma Y, Wang L, Fu T, Gong X, Weintraub M, Wu S, Ding H. Selective tumor cell killing by triptolide in p53 wild-type and p53 mutant ovarian carcinomas. Med Oncol. 2014; 31:14. https://doi. org/10.1007/s12032-014-0014-8.

37. Zheng S, Low K, Wagner S, Yang X, von Briesen H, Zou S. Cytotoxicity of Triptolide and Triptolide loaded polymeric micelles in vitro. Toxicol In vitro. 2011; 25:1557-67. https:// doi.org/10.1016/j.tiv.2011.05.020.

38. Kurokawa M, Zhao C, Reya T, Kornbluth S. Inhibition of apoptosome formation by suppression of Hsp90beta phosphorylation in tyrosine kinase-induced leukemias. Mol Cell Biol. 2008; 28:5494-506. https://doi.org/10.1128/ mcb.00265-08.

39. Gu M, Yu Y, Gunaherath GM, Gunatilaka AA, Li D, Sun D. Structure-activity relationship (SAR) of withanolides to inhibit Hsp90 for its activity in pancreatic cancer cells. Invest New Drugs. 2014; 32:68-74. https://doi.org/10.1007/ s10637-013-9987-y.
40. Zhang T, Hamza A, Cao X, Wang B, Yu S, Zhan CG, Sun D. A novel Hsp90 inhibitor to disrupt Hsp90/Cdc37 complex against pancreatic cancer cells. Mol Cancer Ther. 2008; 7:162-70. https://doi.org/10.1158/1535-7163.mct-07-0484.

41. Weerapana E, Wang C, Simon GM, Richter F, Khare S, Dillon MBD, Bachovchin DA, Mowen K, Baker D, Cravatt $\mathrm{BF}$. Quantitative reactivity profiling predicts functional cysteines in proteomes. Nature. 2010; 468:790-5. https:// doi.org/10.1038/nature09472.

42. Kupchan SM, Schubert RM. Selective alkylation: a biomimetic reaction of the antileukemic triptolides? Science. 1974; 185:791-3.

43. Mollapour M, Neckers L. Post-translational modifications of Hsp90 and their contributions to chaperone regulation. Biochim Biophys Acta. 2012; 1823:648-55. https://doi. org/10.1016/j.bbamcr.2011.07.018.

44. Retzlaff M, Stahl M, Eberl HC, Lagleder S, Beck J, Kessler $\mathrm{H}$, Buchner J. Hsp90 is regulated by a switch point in the C-terminal domain. EMBO Rep. 2009; 10:1147-53. https:// doi.org/10.1038/embor.2009.153.

45. Zhang W, Hirshberg M, McLaughlin SH, Lazar GA, Grossmann JG, Nielsen PR, Sobott F, Robinson CV, Jackson SE, Laue ED. Biochemical and structural studies of the interaction of Cdc37 with Hsp90. J Mol Biol. 2004; 340:891-907.

46. Sreeramulu S, Gande SL, Göbel M, Schwalbe H. Molecular mechanism of inhibition of the human protein complex Hsp90-Cdc37, a kinome chaperone-cochaperone, by triterpene celastrol. Angew Chem Int Ed Engl. 2009; 48:5853-5. https://doi.org/10.1002/anie.200900929.

47. Hong DS, Banerji U, Tavana B, George GC, Aaron J, Kurzrock R. Targeting the molecular chaperone heat shock protein 90 (HSP90): lessons learned and future directions. Cancer Treat Rev. 2013; 39:375-87. https://doi. org/10.1016/j.ctrv.2012.10.001. 